\title{
Wireless Power Transmission
}

\author{
Kuldeep Prajapati ${ }^{1}$, Prof. Ashis Patra ${ }^{2}$, Prof. Tarun Shrivastava ${ }^{3}$ \\ Student, Dept. of Electrical Engineering, MITS Gwalior, M.P., India ${ }^{1}$ \\ Professor, Dept. of Electrical Engineering, MITS Gwalior, M.P., India ${ }^{2}$ \\ Professor, Dept. of Electrical Engineering, MITS Gwalior, M.P., India ${ }^{3}$
}

\begin{abstract}
In this system allow to be transferred from one electrical network to another electrical network without needs for wires exposed contacts basically there have rapid expansion of WPT in cell (mobile) phone charger and electric CFL (bulb) and dynamic charging and electric vehicles also street light, road powered electric be in high stipulation for electric power to be supplied in the upcoming time. vehicles and we used magnetic induction using copper wire with diameter this wireless power transfer filed would Wireless power transfer is a new technology to transfer electrical power without any physical contact between the source and the load. The aim of this paper is to propose the use of a simple, cheap and easy technique for mid-range wireless power transfer. The various technologies available so far for wireless transmission of electricity and the need for a wireless system of energy transmission are discussed here. The core of the used technology is making use of the magnetic resonance concept for transmitting the power wirelessly. A wireless power transfer system for implanted medical devices which uses antenna area 100 times smaller than previous designs is presented.
\end{abstract}

Keywords: Wireless power, energy coupling, Transmission, coils, electrical load.

\section{INTRODUCTION}

In older days people used wires connection to transferred the power from one transmitter to another receiver. In this experiment he achieved the of energy between two tesla coil and successfully used tesla coils to light a wireless CFL or bulb which lay the foundation for the development of wireless power transmission. Microwave used far field high range technology the need wire of wireless power transfer system it allows for charging of multiple device. As an epochmaking technique, wireless power transfer (WPT) incredibly realizes the energy migration in a cordless way [1]-[2]. This seemingly magic way can change our traditional utilization patterns of the energy in various applications, such as portable electronic devices, implanted medical devices, integrated circuits, solar-powered satellites electric vehicles (EVs), unmanned aerial vehicles (UAVs) and so forth. By means of its remarkable characteristics of flexibility, position-free and movability, the WPT technique has been taken as an ideal technical solution for energizing electric-driven devices within some specific regions in the near future, especially for smart home applications. This is achieved by changing the coil geometry as well as allocating large charging benches. It's given high charging speed. It allows for greater spatial freedom between the power sources and the device prevent corrosion and sparking and also required low cost of wire. Wireless power transfer (WPT) or Electromagnetic power transfer is the transmission of electrical energy without wires. Nicole Tesla was the first one to introduce the wireless power transfer in 1891, he began his work on wireless power transmission this laboratory in Colorado, USA. Tesla's successful experiment was the first demonstration of wireless power transfer concept The Wardenclyffe tower. We live in a world where every day new technologies are invented daily life. The need of wireless power transfer system it allow for charging.

\section{SYSTEM STRUCTURE}

Out of the numerous wireless energy transfer techniques that have been proposed in research labs and in theory papers, three of them stand out the most. The first method utilizes directed microwaves as the source of wireless energy and rectennas as the converters of microwaves back to electricity, the second scheme makes use of laser technology to beam photons onto photovoltaic cells which in turn convert the photons into electricity, and the third plan implements mutual induction between two coils operating at the same Wireless power transfer is a very efficient and economical way of transfer power from one point to another point for short as well as long distances. There are so many problems occurring by transmission of power by wires which can be overcome by Wireless Power Transfer. It reduces losses associated with wires. Wireless Power Transfer working is based upon Faraday law of Electromagnetic induction. Wireless Power Transfer consist of two sides that are transmitter and the receiver side. When main AC power of $230 \mathrm{~V}$ is supplied to the circuit, a high frequency step down transformer connected across it converts $230 \mathrm{~V}$ to $13 \mathrm{~V}$. The charging device receives Direct Current (DC) from a power source which is then converted to Alternating Current (AC) by the transmitter. The 
International Journal of Innovative Research in Electrical, Electronics, Instrumentation and Control Engineering

Vol. 9, Issue 6, June 2021

\section{DOI 10.17148/IJIREEICE.2021.9601}

rectifier converts AC to DC Voltage. The Oscillator connected across it produces continuous, repeated and alternating waveform. Due to the AC current, the transmitting coil within the transmitter becomes energized and produces magnetic field. When a receiving coils placed near the transmitter, current is induced in receiving coil. Hence current will flow through the receiving coil by which we can use it for transmission of power. The charging cables are connected over the receiver side to connect the devices. Hence by connecting any devices to the charging cables we can charge our device.

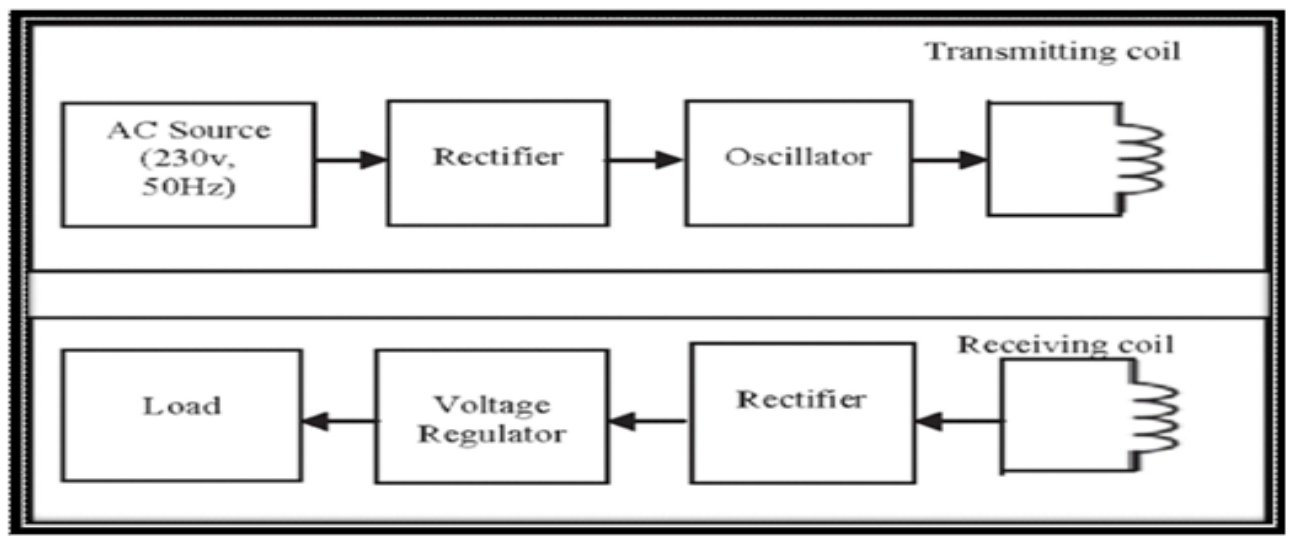

Fig.1: Block Diagram of Wireless Power Transfer System

\section{III.ENERGY COUPLING}

Energy coupling occurs when the energy produced by one reaction or system is used to drive another reaction or system. endergonic: Describing a reaction that absorbs (heat) energy from its environment. exergonic Describing a reaction that releases energy (heat) into its environment.

The transfer of energy.

(i) Magnetic coupling

(ii) Inductive coupling

Simplest wireless energy coupling is a transformer

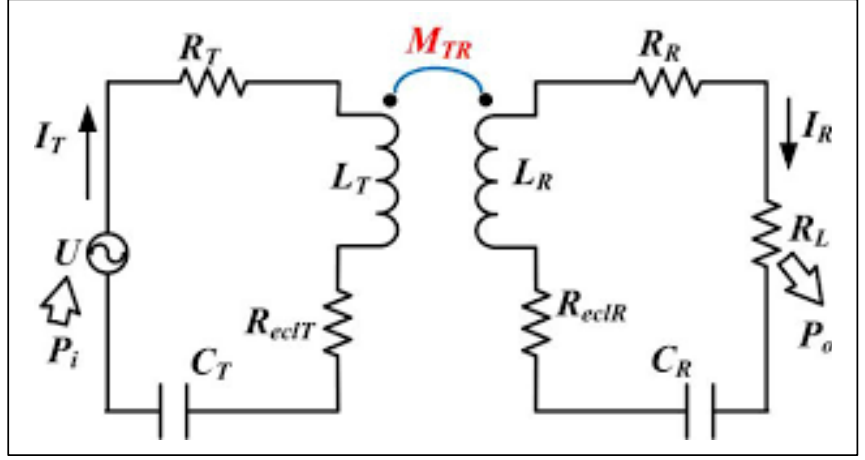

Fig.2 Energy coupling circuit diagram

(i)

Magnetic coupling

A magnetic coupling is a coupling that transfers torque from one shaft to another, but using a magnetic field rather than a physical mechanical connection.

Magnetic shaft couplings are most often used for liquid pumps and propeller systems, since a static, physical barrier can be placed between the two shafts to separate the fluid from the motor operating in air. 


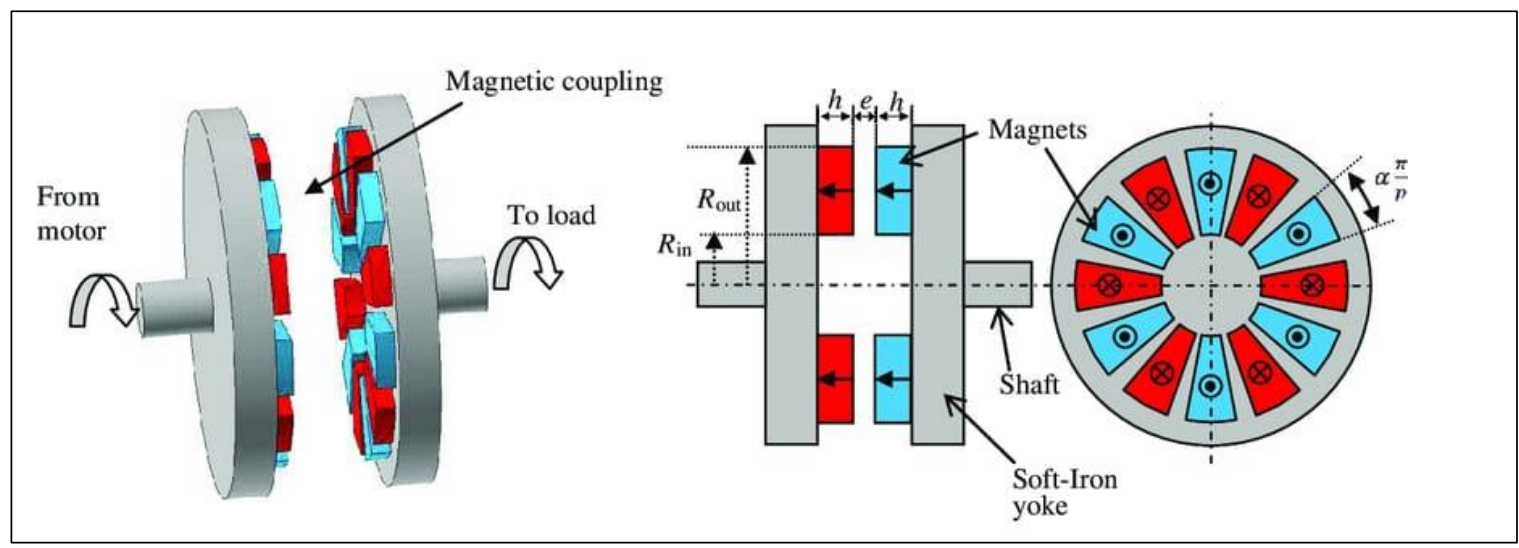

Fig.3 Magnetic coupling

(ii) INDUCTIVE COUPLING

In electrical engineering, two conductors are said to be inductively coupled or magnetically coupled when they are configured such that a change in current through one wire induces a voltage across the ends of the other wire through electromagnetic induction. A changing current through the first wire creates a changing magnetic field around it by Ampere's circuital law. The changing magnetic field induces an electromotive force (EMF or voltage) in the second wire by Faraday's law of induction. The amount of inductive coupling between two conductors is measured by their mutual inductance.

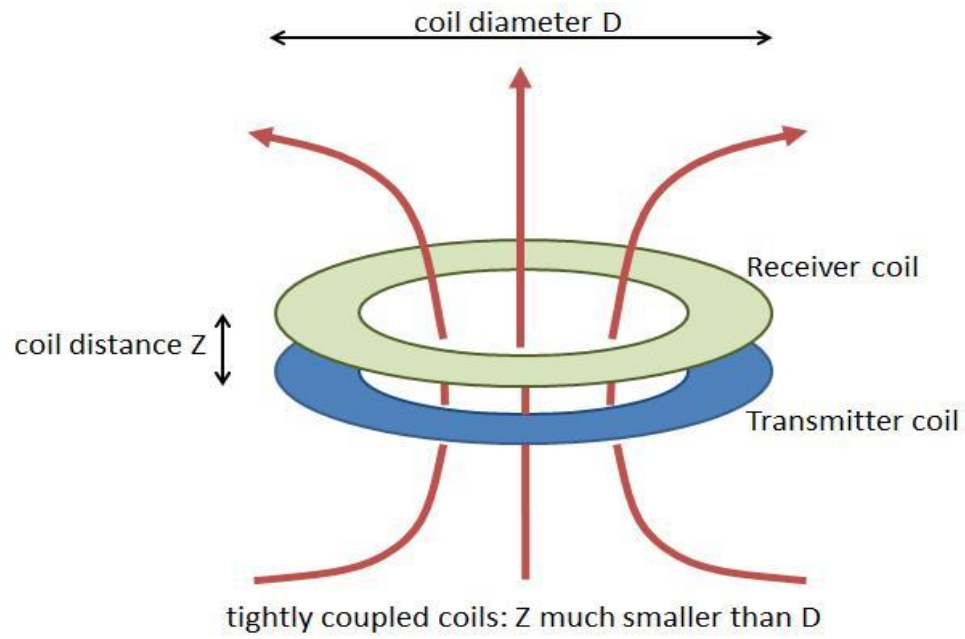

\section{(iii) WiTricity}

Fig.4 Inductive coupling

- $\quad$ Based on RIC.

- $\quad$ Led by MIT's Marin Soljacic.

- Energy transfer wirelessly for a distance just

- $\quad$ more than $2 \mathrm{~m}$. Coils were helical shape.

- No capacitor was used.

- Efficiency achieved was around $40 \%$ 


\section{IV.APPLICATION}

- $\quad$ Near field energy transfer.

- $\quad$ Electric automobile charging.

- $\quad$ Consumer electronics.

- Industrial purposes

- Smart phone, Electric bulb, digital camera.

- $\quad$ Public access charging terminal

\section{ADVANTAGE}

- $\quad$ No wires

- $\quad$ No e-waste.

- $\quad$ Need for battery is eliminated.

- $\quad$ Efficient energy transfer using RIC

- Harmless, if field strengths under safety levels.

- $\quad$ Maintenance cost is less

- $\quad$ Highly resonate strong coupling provides efficiency over distance.

\section{VI.DISADVANTAGE}

- $\quad$ Distance constraint.

- $\quad$ Field strengths have to be under safety levels.

- Initial cost is high.

- $\quad$ In RIC, tuning is difficult.

- $\quad$ High frequency signals must be the supply.

- $\quad$ Air ionization technique is not feasible

\section{LITERATURE REVIEW}

This research paper simply explains the circuit that is used to glow a CFL and to charge a mobile phone by using two inductively coupled coils. Our project uses the principle of INDUCTIVE COUPLING for wireless power transfer, that is, the alternating magnetic field around a transmitter coil is induced in the receiver coil kept near to it through electromagnetic induction. The main components used here are a power supply, a transmitter and a receiver coil. As the power supply reaches transmitter coil; a magnetic field is produced, which is then induced in the receiver coil. Thus, the electrical power reaches to the load without making any physical connections and the CFL glows and the mobile starts to charge load of project

\section{FUTURE SCOPE}

In future we can use electric appliances by using electricity without wire. Wireless power transmission is the way to transfer power without using wire. Wireless power transmission helps to connect those area where people are unable to get a suitable power source. Everyone can get clean and green wireless power. In future all the devices will relate to the power supply source wirelessly." Really, it's about having power everywhere you are, and not having to be limited by 


\section{IJIREEICE \\ International Journal of Innovative Research in Electrical, Electronics, Instrumentation and Control Engineering \\ Vol. 9, Issue 6, June 2021 \\ DOI 10.17148/IJIREEICE.2021.9601}

the amount of power you can carry with you in a batter or some other matter," explains Joshua Schwannecke, an engineering manager at Fulton innovate

\section{IX.CONCLUSION}

This paper assessed the state of wireless power transfer research based on the publication in the most important science and technology journals during the decade of 2001-2013. Wireless power transfer technology has the potential to change our planet to so many different levels. It not only reduces the need for cables or wires, it can also help in dealing with the problems like global warming, increasing pollution, unnecessary power losses occurring due to wired power transmission. Wireless Power Transfer can be seen in the near future due to the new advancements made in the technologies. Whether it be handheld device charging or the electrical energy transference using wireless power transfer technology, all these can be done easily in the future by doing proper studies related to this technology.

\section{REFRENCES}

1) A. Kurs, A. Karalis, R. Moffatt, et al., "Wireless power transfer via strongly coupled magnetic resonances," Science, Vol. 317, pp. 83-86,

2007.

2) B. L. Cannon, J. F. Hoburg, D. D. Stancil, et al., "Magnetic Resonant Coupling As a Potential Means for Wireless Power Transfer to Multiple

Small Receivers," IEEE Trans. Power Electronics, Vol. 24, No. 7, pp. 1819-1825, 2009.

3) A. P. Sample, D. A. Meyer, J. R. Smith, “Analysis, Experimental Results, and Range Adaptation of Magnetically Coupled Resonators for

Wireless Power Transfer,” IEEE Trans. Industrial Electronics, Vol. 58, No. 2, pp. 544-554, 2011

4) Z. N. Low, R. A. Chinga, R. Tseng, et al., "Design and Test of a High-Power High-Efficiency Loosely Coupled Planar Wireless Power Transfer

System,” IEEE Trans. Industrial Electronics, Vol. 56, No. 5, pp. 1801-1812, 2009.

5) G. Vandevoorde, R. Puers, "Wireless energy transfer for stand-alone systems: a comparison between low and highpower applicability,"

Sensor and Actuators a: Physical, Vol. 92, No. 1-3, pp. 305-311, 2001.

6) T. Imura, Y. Hori, “Maximizing Air Gap and Efficiency of Magnetic Resonant Coupling for Wireless Power Transfer Using Equivalent Circuit

and Neumann Formula," IEEE Trans. Industrial Electronics, Vol. 58, No. 10, pp. 4746-4752, 2011

7) Ch. J. Chen; T. H. Chu, Ch. L. Lin, et al. "A Study of Loosely Coupled Coils for Wireless Power Transfer," IEEE Trans. Circuits and Systems II-

Express Briefs, Vol. 57, No. 7, pp. 536-540, 2010.

8) Tahsin, N.M., Siddiqui, M.M., Zaman, M.A., \& Kayes, M.I. (2012). Wireless charger for low power devices using inductive coupling.

https://www.academia.edu/2329757/Wireless_Charger_for_low_power_devices_using_inductive_coupling.

9) Melvin D. Saunders. (2019). Wireless electricity of Nikola Tesla. Available at: http://www.mindcourse.com/wireless.html.

10) Vikash Choudhary, Satendar Pal Singh, Vikash Kumar, \& Deepak Prashar. (2011). Wireless power transmission: An innovative idea.

International Journal of Educational Planning \& Administration, 1(3), 203-210.

11) Dombi J. (1982). Basic concepts for a theory of evaluation: The aggregative operator. European Jr. Operation Research, 10, 282-293. 